\title{
AVALIAÇÃO DA REGIÃO ESPAÇADORA 16S-23S DNAR COMO MARCADOR MOLECULAR PARA DIFERENCIAÇÃO DE ACIDOVORAX AVENAE SUBSP. CATTLEYAE E BURKHOLDERIA GLADIOLI PV. GLADIOLI PATOGÊNICAS A ORQUÍDEAS
}

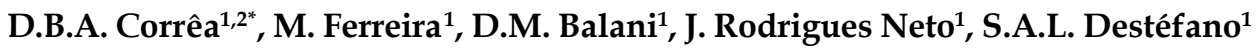

${ }^{1}$ Instituto Biológico, Centro Experimental Central do Instituto Biológico, CP 70, CEP13001-970, Campinas, SP, Brasil. E-mail: suzete@biologico.sp.gov.br

\section{RESUMO}

\begin{abstract}
A região espaçadora 16S-23SDNAr foi avaliada como marcador molecular para a diferenciação dos patógenos de orquídeas, Acidovorax avenae subsp. cattleyae e Burkholderia gladioli pv. gladioli. Outras espécies pertencentes a esses dois gêneros comoB. gladiolipv. alliicola, A. avenaesubsp. avenae, A. avenae subsp. citrulli, A. anthurii, A. facilis, A. delafieldii e A. konjaci também foram analisadas. A amplificação por PCR dessa região produziu um fragmento de aproximadamente 1.100 pares de bases para todas as linhagens testadas. Os produtos obtidos foram submetidos a digestões com as enzimas Afa I, Alu I, Hae III e Hpa II e os resultados mostraram perfis distintos de RFLP para A. avenae subsp. cattleyae de B. gladioli pv. gladioli com todas as endonucleases testadas. As seqüências da região espaçadora 16S-23S DNAr foram alinhadas e a análise filogenética confirmou as diferenças entre A. avenae subsp. cattleyae e B. gladioli pv. gladioli. A técnica de PCR-RFLP mostrouse eficiente e muito útil para a identificação desses patógenos, uma vez que eles causam sintomas muito semelhantes em orquídeas.
\end{abstract}

PALAVRAS-CHAVE: PCR-RFLP, diagnóstico de fitobactérias, Phalaenopsis sp.

\section{ABSTRACT}

EVALUATION OF 16S-23S rDNA SPACER REGION AS A MOLECULAR MARKER TO DIFFERENTIATION OF ACIDOVORAX AVENAE SUBSP. CATTLEYAE AND BURKHOLDERIA GLADIOLI PV. GLADIOLI PATHOGENIC TO ORCHIDS. The 16S-23S rDNA spacer region was evaluated as a molecular marker to differentiation of orchids pathogens, Acidovorax avenae subsp. cattleyae and Burkholderia gladioli pv. gladioli. Other species belonging to the two genera such as $B$. gladioli pv. alliicola, A. avenae subsp. avenae, A. avenae subsp. citrulli, A. anthurii, A. facilis, A. delafieldii and A. konjaci were also analyzed. The PCR amplification of the 16S-23S rDNA spacer region produced a fragment of 1,100 base pairs. The products obtained from all strains were digested with Afa I, Alu I, Hae III and Hpa II and the results showed distinct RFLP patterns for each endonuclease tested. The sequences of 16S-23S rDNA spacer region were aligned and the phylogenetic analysis confirmed the differences between A. avenae subsp. cattleyae e B. gladioli pv. gladioli. The PCR-RFLP technique was very efficient and useful to the identification of these pathogens since they cause very similar symptoms in orchids.

KEY WORDS: PCR-RFLP, phytobacteria diagnosis, Phalaenopsis sp.

\section{INTRODUÇÃO}

As exportações brasileiras de flores e plantas ornamentais vêm se destacando expressivamente nos últimos anos, principalmente a partir do ano 2000, com crescimento contínuo tanto no valor das exportações quanto no saldo comercial. O setor no
Brasil, que vem crescendo a cada ano, acumulou vendas internacionais no valor de US\$29,6 milhões em 2006, representando um aumento de $14,8 \%$ em relação ao ano anterior, segundo a Secretaria de Comércio Exterior, Ministério do Desenvolvimento, Indústria e Comércio Exterior (SECEX/MDCI) (KIYUnA et al., 2007).

\footnotetext{
${ }^{2}$ Universidade Estadual de Campinas-UNICAMP, Campinas, SP, Brasil.

*Bolsista CNPq/PIBIC.
} 
As mudas de plantas ornamentais representam o principal produto de exportação brasileira na área de flores e plantas. O segmento apresentou aumento nas exportações nos últimos anos, atestando o vigor e a agressividade do exportador nacional. Omesmoavanço pode ser verificado nas exportações de mudas de orquídeas que acumularam vendas de US\$ 45 mil no primeiro trimestre de 2005, representando um crescimento de $102,37 \%$ em relação ao mesmo período de 2004. Os principais mercados internacionais consumidores de orquídeas são Reino Unido, Estados Unidos, Japão, Hong Kong e Alemanha (Gondim et al., 2005).

Bactérias fitopatogênicas dos gênerosAcidovorax, Burkholderia, Dickeya (sin. Erwinia) e Pectobacterium (sin. Erwinia) causam diversos prejuízos à exploração comercial de orquídeas, podendo inclusive provocar a morte de plantas afetadas em curto espaço de tempo. Acidovorax avenae subsp. cattleyae causa necrose de folhas, morte de gemas e de plantas. As folhas infectadas apresentam inicialmente lesões irregulares e de diferentes tamanhos, podendo atingir todo o limbo e o pseudocaule, e resultar na morte da planta. Burkholderia gladioli pv. gladioli causa lesões foliares escuras, grosseiramente circulares, que podem levar à destruição do limbo foliar (Malavolta Junior; Almeida, 1998).

Os sintomas de manchas foliares provocados por A. avenae subsp. cattleyae e B. gladioli pv. gladioli são muito similares e a identificação do patógeno está baseada em testes bioquímicos convencionais. O diagnóstico com base nos sintomas pode ser efetuado, porém será apenas presuntivo e necessitará de confirmação em laboratório. As técnicas convencionais demandam longo tempo, uma vez que exigem a realização de testes cujos resultados podem requerer dias ou semanas para avaliação. Os métodos moleculares baseados nas análises de seqüências de DNA oferecem maior precisão e sensibilidade quando comparados aos métodos convencionais de análise de caracteres fenotípicos, pois utilizam um critério universal presenteem todos os organismos, permitindo, assim, a comparação entre grupos de microrganismos que desempenham funções diferentes no ambiente.

Técnicas moleculares como RFLP (Restriction Fragment Length Polymosphism), amplificação por PCR (Polymerase Chain Reaction), seqüências 16S do DNA ribossomal (DNAr), região espaçadora 16S-23S DNAr, entre outras, vêm sendo aplicadas no estudo da diversidade dos fitopatógenos em geral acarretando profundas alterações na taxonomia das fitobactérias, e resultando em novas composições de grupos e/ou espécies, inclusive com a proposição de novas espécies e patovares, bem como o conhecimento em nível inter e infra-específico.
Dados de seqüências da região espaçadora entre os genes 16S-23S DNAr têm se acumulado em anos recentes, e o alinhamento de seqüências disponíveis em bancos de dados evidenciou que não existem regiões altamente conservadas nessa molécula eque pode ocorrer variação considerável entre as espécies, tanto no tamanho como na seqüência de bases (GÜrtler; Stanisich, 1996).

O presente trabalho teve por objetivo a avaliação da região espaçadora $165-23 S$ DNAr como marcador molecular para a diferenciação de $A$. avenae subsp. cattleyae e B. gladioli pv. gladioli patogênicas a orquídeas.

\section{MATERIAL E MÉTODOS}

Linhagens. As linhagens bacterianas utilizadas no presente estudo foram cedidas pela Coleção de Culturas de Fitobactérias do Instituto Biológico (IBSBF), Laboratório de Bacteriologia Vegetal, Centro Experimental do Instituto Biológico, Campinas, SP e estãolistadas na Tabela 1. As linhagens, preservadas por liofilização, foram reativadas e cresceram em meio NA (Extrato de carne $3 \mathrm{~g}$; Peptona $5 \mathrm{~g}$; $\mathrm{NaCl} 5 \mathrm{~g}$ e ágar $15 \mathrm{~g}$ por litro), a $28^{\circ} \mathrm{C} / 48 \mathrm{~h}$. Para a extração de DNA, as linhagens foram cultivadas em $5 \mathrm{~mL}$ de meio NB (NA sem adição de Ágar) por 16-18h/28 $\mathrm{C} / 180$ rpm.

Extração de DNA e amplificação. O DNA cromossômico foi extraído segundo a metodologia descrita por Pitcher et al. (1989) e a pureza e quantificação do DNA das amostras foram realizadas através de eletroforese em gel de agarose 0,6\% em tampão TAE $1 X$ (0,04 M Tris-acetato/ 0,001 M EDTA). Os géis foram corados com brometo de etídeo $(0,1 \mathrm{mg} / \mathrm{mL})$, visualizados em transiluminador sob luz ultra-violeta e fotografados em sistema digital Alpha Innotech 2200. Para realização da PCR foram utilizados aproximadamente 200 ng de DNA genômico em reações de 25 $\mathrm{mL}$ contendo 2,0 $\mathrm{U}$ de Taq polimerase (GE Healthcare); tampão da enzima Taq 1X;0,4 mM de uma mistura de dNTPs e $0,4 \mathrm{mM}$ de cada primer. O programa de amplificação das amostras consistiu de um ciclo de desnaturação inicial a $95^{\circ} \mathrm{C} / 2 \mathrm{~min}$.; seguido de 30 ciclos a $94^{\circ} \mathrm{C} /$ $1 \mathrm{~min} . ; 60^{\circ} \mathrm{C} / 1 \mathrm{~min}$. e $72^{\circ} \mathrm{C} / 3 \mathrm{~min}$; e um ciclo a $72^{\circ}$ $\mathrm{C} / 5 \mathrm{~min}$. (extensão final). Os experimentos foram realizados em termociclador da marca Perkin Elmer modelo 9700. O par de primers utilizado para a amplificação da região espaçadora 16S23S foi pHr [5' TGC GGC TGG ATC ACC TCC TT 3'] (Massol-Deya et al., 1995) e p23Suni322-anti [5' GGT TCT TTT CAC CTT TCC CTC 3'] (Honeycut et al., 1995). 
Tabela 1 - Linhagens utilizadas neste estudo.

\begin{tabular}{|c|c|c|c|}
\hline Linhagens & IBSBF & Hospedeiro & Origem \\
\hline \multirow[t]{2}{*}{ Acidovorax avenae subsp. cattleyae } & $209^{P}$ & Orquídea (gênero e espécie não caracterizados) & USA \\
\hline & 1009 & Phalaenopsis sp. & Brasil \\
\hline \multirow[t]{2}{*}{ Acidovorax avenae subsp. avenae } & $1854^{\mathrm{T}}$ & Zea mays & USA \\
\hline & 342 & Saccharum officinarum & Ilhas Reunião \\
\hline \multirow[t]{2}{*}{ Acidovorax avenae subsp. citrulli } & $1851^{\mathrm{P}}$ & Citrullus lanatus & USA \\
\hline & 1521 & Cucumis melo & Brasil \\
\hline \multirow[t]{2}{*}{ Acidovorax anthurii } & $1977^{\mathrm{T}}$ & Anthurium sp. & Martinique \\
\hline & 1542 & Anthurium sp. & Martinique \\
\hline Acidovorax konjaci & $1973^{\mathrm{T}}$ & Amorphophallus rivieri & Japão \\
\hline Acidovorax delafieldii & $1978^{\mathrm{T}}$ & Solo & USA \\
\hline Acidovorax facilis & $1976^{\mathrm{T}}$ & Solo & USA \\
\hline \multirow[t]{2}{*}{ Burkholderia gladioli pv. Gladioli } & $546^{\mathrm{T}}$ & Gladiolus sp. & USA \\
\hline & 1277 & Orquídea (gênero e espécie não caracterizados) & Brasil \\
\hline Burkholderia gladioli pv. alliicola & $534^{\mathrm{P}}$ & Allium cepa & USA \\
\hline Xanthomonas sp.* & - & - & - \\
\hline
\end{tabular}

Análise dos fragmentos de restrição. Do produto gerado da amplificação por PCR, 4 mL foram digeridos individualmente com as seguintes enzimas de restrição: Afa I, Alu I, Hae III ou Hpa II em reações de 15 $\mathrm{mL}$ contendo $5 \mathrm{U}$ da enzima por reação. As condições de temperatura foram empregadas de acordo com as recomendações do fabricante (Fermentas). A observação do perfil de restrição obtido foi realizada através de eletroforese em gel de agarose 3\%.

Sequenciamento e análise filogenética da região espaçadora 16S-23S DNAr.Os produtos deamplificação correspondentes à região espaçadora 16S-23S DNAr das linhagens deAcidovorax spp.eBurkholderia spp. foram purificados utilizando-se o kit GFX PCR DNA and Gel Band Purification (Amersham Biosciences) de acordo com as recomendações do fabricante, para posterior seqüenciamento. Após as purificações, oDNAdas diferenteslinhagens foiquantificado em geldeagarose $1 \%$. As reações para sequenciamento foramefetuadascomokitBigDye(Applied Biosystems) utilizando-se o par de primers pHr e p23Suni322-anti e a purificação da reação foi feita segund o o fabricante do kit. As amostras deDNA foram secas, suspensas em tampão apropriado e submetidas à eletroforese no seqüenciador automático, marca Applied Biosystems, modelo ABI Prism 377. Para a comparaçãofoi utilizada a região espaçadora 16S-23S das linhagens seqüenciadas neste estudo assim como de uma linhagem de Xanthomonas sp., cuja seqüência foi obtida na base de dados do GenBank e foi utilizada como grupo externo na análise filogenética. As sequências foram editadas utilizando-se o programa BioEdit (HALL,1999) ealinhadascomouso do programa ClustalX(THOMPSON etal., 1997). As seqüências alinhadas foram utilizadas para a construção de uma árvore filogenética usandose o método Neighbour-Joining no programa MEGA (Kumar et al., 2004). Análises de bootstrap com 1000 repetições foram realizadas para prover suporte para aos braços da árvore filogenética obtida.

\section{RESULTADOS E DISCUSSÃO}

A amplificação da região espaçadora 16S-23S DNAr de $A$. avenae subsp. avenae (IBSBF $1854^{\mathrm{T}}$ ), A. avenae subsp. citrulli (IBSBF1851 ${ }^{\mathrm{P}}$ ), A. avenae subsp. cattleyae (IBSBF 209 $)$, A. anthurii (IBSBF 1977'T), A. konjaci (IBSBF 1973 $)$, A. delafieldii (IBSBF 1978 $)$, A. facilis (IBSBF 1976 ${ }^{\mathrm{T}}$ ), B. gladioli pv. alliicola (IBSBF $534^{\mathrm{P}}$ ) e B. gladioli pv. gladioli (IBSBF $546^{\mathrm{T}}$ ) produziu um fragmento de aproximadamente 1.100 pares de bases (pb) para todas as linhagens testadas. Os produtos resultantes da amplificação foram submetidos à digestão com as endonucleases e apresentaram sítios de restrição para todas as enzimas testadas, sendo detectado polimorfismo entre a maioria das linhagens analisadas (Figs. 1 e 2).

Os perfis de restrição das linhagens deBurkholderia foram idênticos nas digestões com as enzimasHae III, $H p a$ II e $A l u$ I. No entanto, a digestão com a enzima $A f a$ I gerou diferentes perfis entre os patovares de Burkholderia gladioli. O padrão de bandas de B. g. pv. gladioli, patogênica a orquídeas, mostrou fragmentos de aproximadamente 900 e 100 pb. B. g. pv. allliicola exibiu um perfil de restrição distinto com fragmentos de aproximadamente 500, 340 e 100 pb (Fig.1). 


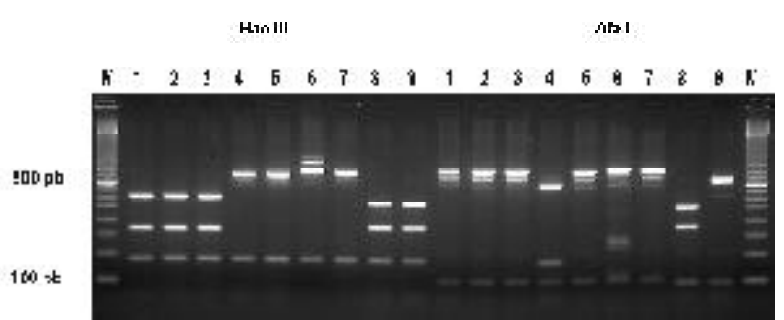

Fig. 1 - Digestão dos produtos de amplificação da região espaçadora 16S-23S DNAr com as enzimas Hae III e Afa I. (M) marcador de peso molecular de 100pb (Amersham Biosciences); (1) A. a. subsp. avenae (IBSBF 1854'); (2) A. $a$. subsp. cattleyae (IBSBF 209P); (3) A. a. subsp. citrulli (IBSBF 1851 ${ }^{\mathrm{P}}$ ); (4) A. anthurii (IBSBF 1977'); (5) A. konjaci (IBSBF 1973 ${ }^{\mathrm{T}}$; (6) A. delafieldii (IBSBF 1978); (7) A. facilis (IBSBF 1976 ${ }^{\mathrm{T}}$; (8) B. g. pv. alliicola (IBSBF 534 ${ }^{\mathrm{P}}$ ); (9) B. g. pv. gladioli $\left(\right.$ IBSBF $\left.546^{\mathrm{T}}\right)$.

Com relação às linhagens do gênero Acidovorax, nas digestões com Alu I, Hae III e Hpa II as linhagens da espécie $A$. avenae apresentaram perfis distintos das outras espécies do gênero. Nos testes com as enzimas $A f a$ I, Alu I e Hae III as linhagens A. avenae subsp. cattleyae, A. a. subsp. citrulli e A. a. subsp. avenae apresentaram perfis idênticos, o que evidenciou alta similaridade dessa região nessas subespécies. Das enzimas utilizadas apenas Hpa II gerou perfil que permitisse a diferenciação de $A$. $a$. subsp. citrulli das demais subespécies que nova-

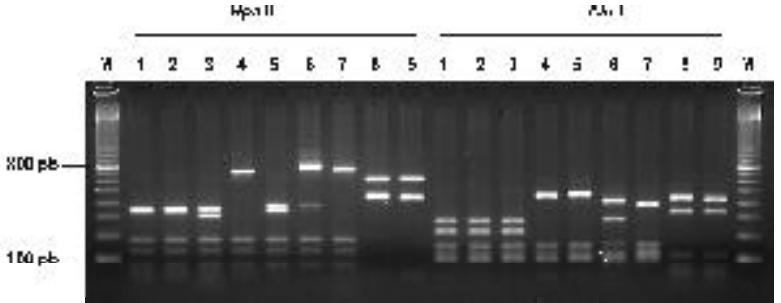

Fig. 2 - Digestão dos produtos de amplificação da região espaçadora 16S-23S DNAr com as enzimas Hpa II e Alu I. (M) marcador de peso molecular de 100pb (Amersham Biosciences); (1) A. a. subsp. avenae (IBSBF 1854); (2) A. $a$. subsp. cattleyae (IBSBF 209 $)$; (3) A. a. subsp. citrulli (IBSBF 1851 ${ }^{\mathrm{P}}$ ); (4) A. anthurii (IBSBF 1977 ); (5) A. konjaci (IBSBF 1973'); (6) A. delafieldii (IBSBF 1978 $)$; (7) A. facilis (IBSBF 1976 ${ }^{\mathrm{T}}$ ); (8) B. g. pv. alliicola (IBSBF 534 ${ }^{\mathrm{P}}$ ); (9) B. g. pv. gladioli $\left(\right.$ IBSBF $\left.546^{\mathrm{T}}\right)$.

mente apresentaram perfis idênticos. $\mathrm{O}$ padrão de restrição de A. avenae subsp. cattleyae e $A$. $a$. subsp. avenae, mostrou fragmentos de aproximadamente $350,180,140$ e outros menores que $100 \mathrm{pb}$. A. $a$. subsp. citrullise diferenciou das demais subespécies por apresentar, além dos fragmentos já citados, uma banda de 300 pb (Fig. 2).

Os patógenos de orquídeas, $A$. avenae subsp. cattleyae e B. g. pv. gladioli, apresentaram perfis de restrição distintos com todas enzimas utilizadas e com isso puderam ser claramente diferenciados.
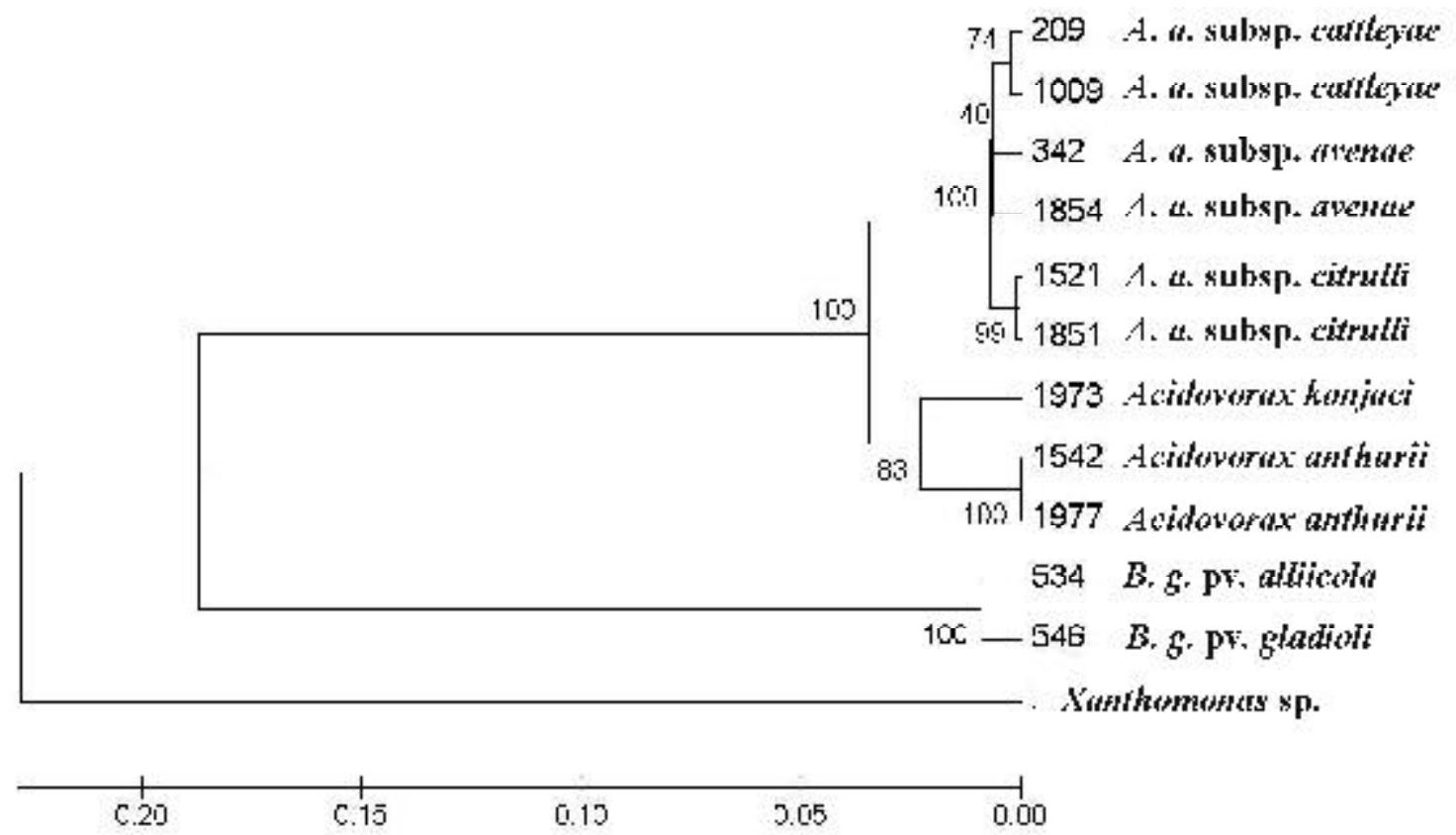

Fig. 3 - Árvore filogenética construída usando o métodoNeighbour-Joining, baseada em seqüências da região espaçadora 16S-23S DNAr de linhagens de Acidovorax e Burkholderia, com Xanthomonas sp. como grupo externo. O número sobre os braços são valores de bootstrap obtidos em 1000 repetições (expressos em porcentagem). 
A partir do resultado do sequenciamento, as seqüências correspondentes à região espaçadora 16S23S DNAr foram alinhadas para a construção de uma árvore filogenética (Fig. 3). A análise da árvore revelou que as linhagens do gênero Burkholderia e as pertencentes ao gênero Acidovorax formaram grupos distintos. Além disso, as linhagens representantes do gênero Acidovorax formaram dois agrupamentos principais separando as linhagens da espécie $A$. avenae das demais espécies do gênero. Em cada um dos grupos, isolados de uma mesma espécie se mostraram muito similares ou idênticos entre si e o que os diferenciaram foram poucas bases distintas presentes em suas seqüências, como observado com as subespécies de A. avenae. O dendrograma mostra, também, alta similaridade entre os patovares da espécie Burkholderia gladioli, as quais formaram um agrupamento bem distinto do grupo de Acidovorax, indicando que as seqüências da região espaçadora 16S-23S DNAr, podem distinguir claramente esses dois gêneros.

A amplificação por PCR tem permitido a análise da região espaçadora 16S-23S de microrganismos com o propósito de detectar heterogeneidade entre e dentro de espécies (BARRY et al., 1991; JENSEN et al., 1993; Kostman et al., 1995), possibilitando a identificação e tipagem dos organismos. Desse modo, MANCEAU;HORvaIs (1997) obtiveram a diferenciação em nível infra-específico de linhagens de Pseudomonas syringae por meio da técnica de PCRRFLP da região espaçadora. Xanthomonas patogênicas aos citros (Destéfano;R odrigues Neto, 2002) e à cana-de-açúcar (Destéfano et al., 2003) também puderam ser diferenciadas por essa metodologia. A partir da análise de seqüências variáveis dessa região em linhagens de dois patovares associados a doenças em cereais, MAEset al. (1996) desenharam primers específicos para os diversos patovares de Xanthomonas que causam CLS (Cereal Leaf Streak).

No presente estudo, os resultados obtidos reforçaram a aplicabilidade da região espaçadora na diferenciação de microrganismos. OPCR-RFLP bem como a árvore filogenética, construída a partir de dados de alinhamento das seqüências da região espaçadora 16S-23S DNAr, revelaram que há grandes diferenças nessa região entre os patógenos de orquídeas. A técnica empregada mostrou-se eficiente para o diagnóstico de A. a.subsp. cattleyae eB. g.pv. gladioli, uma vez que esses microrganismos causam sintomas muito semelhantes naqueles hospedeiros. Esses resultados demonstram a possibilidade de utilização desta região para o desenho de primers específicos para a detecção de cada um desses patógenos, otimizando assim, a metodologia de diagnóstico desenvolvida.

\section{AGRADECIMENTOS}

Ao Conselho Nacional de Desenvolvimento Científico e Tecnológico (CNPq) pela bolsa de Iniciação Científica PIBIC/IB concedida para a aluna Daniele Bussioli Alves Corrêa e ao Laboratório de Bacteriologia Vegetal (LBV) do Centro Experimental Central do Instituto Biológico (CEIB), Campinas (SP) pela cessão das instalações para a condução dos experimentos.

REFERÊNCIAS

Barry, T.; Colleran,G.;Glennon, M.;Dunican, L.K.;GannON, F. The 16S/23S ribosomal spacer region as a target for DNA probes to identify eubacteria. PCR Methods and Applications, v.1, p.51-56, 1991.

DestéFAnO, S.A.L.; RodRIGUes Neto, J. Rapid Differentiation of Xanthomonas strains causing disease in citrus plants based on Polymerase Chain Reaction-amplified ribosomal DNA spacer polymorphisms. Summa Phytopathologica, v.28, p.167-172, 2002.

Destéfano, S.A.L.;A lmeida,I.M.G.;Rodrigues Neto,J.;Ferreira, M.; BALANI, D.M. Differentiation of Xanthomonas species pathogenic to sugarcane by PCR-RFLP analysis. European Journal of Plant Pathology, v.109, p.283-288, 2003.

Gondim, A.; Gondim, P.; Lage, M.; Bonelli, A.; Fraga, F.; Teixeira, G.; T AVAREs, K. Sudeste-São Paulo: Olíder do agronegócio de flores. Revista Sebrae - Agronegócios, n.1, p.36-37, 2005. Disponível em: <http:// www.sebrae.com.br/br/revista_agro/sp.asp>. Acesso em: 12 ago. 2006.

GÜRTLER, V.;S TANISICH, V.A. New approaches to typing and identification of bacteria using the 16S-23S rDNA spacer region. Microbiology, v.142, p.3-16, 1996.

HALL, T.A. BioEdit: a user-friendly biological sequence alignment editor and analysis program for Windows 95/98/NT. Nucleic Acids Symposium Series, v.41, p.9598, 1999.

Honeycut, R.J.; Sobral, B.W.S.; McClelland, M. Trna intergenic spacers reveal polymorphism diagnostic of Xanthomonas albilineans. Microbiology, v.141, p.32293239, 1995.

Jensen, M.A.; Webster, J.A.; Straus, N. Rapid identification of bacteria on the basis of polymerase chain reactionamplified ribosomal DNA spacer polymorphisms. Applied and Environmental Microbiology, v.59, n.4, p.945952, 1993.

Kiyuna, I.; Angelo, J.A.; Coelho, P.J. Floricultura: desempenho do comércio exterior em 2006. Análises e Indicadores do Agronegócio, São Paulo, v. 1, n. 2, 2007. Disponível em: < http://www.iea.sp.gov.br/OUT/ verTexto.php?codTexto=8748>. Acesso em: 10 jul. 2007.

Kostman, J.R.; Alden, M.B.; Mair, M.; Edlind, T.D.; Lipuma, J.J.; STULl, T.L. A universal approach to bacterial molecular epidemiology by polymerase chain reaction ribotyping. Journal of Infection Disease, v.171, p.204-208, 1995. 
Kumar, S.; Tamura, K.; NeI, M. Mega 3: Integrated software for Molecular Evolutionary Genetics Analysis and sequence alignment, versão 3.1. Briefings in Bioinformatics, v.5, p.150-163, 2004.

Maes, M.;G arbeva,P.;K Amoen, O. Recognition and detection in seed of the Xanthomonas pathogens that cause cereal leak streak using rDNA spacer sequences and polymerase chain reaction. Phytopathology, v.86, n.1, p.63-69, 1996.

Malavolta Junior.; V.A.; Almeida, I.M.G. Doenças Bacterianas. In: Bergmann, E.C.; Alexandre, M.A.V. (Coord.). Aspectos fitossanitários das orquídeas. São Paulo: Instituto Biológico, 1998. p.40-44. (Boletim Técnico, n.11)

Manceau, C.; Horvais, A. Assessment of genetic diversity among strains of Pseudomonas syringae by PCRRestrictionFragmentLengthPolymorphismanalysis of rRNA operons with special emphasis on P. syringae pv. tomato. Applied and Environmental Microbiology, v.63, n.2, p.498-505, 1997.
Massol-Deya, A.A.; Obelson, D.A.; Hckey, R.F.; Tiedje, J.M. Bacterial community fingerprinting of amplified $16 \mathrm{~S}$ and 16S-23S ribosomal DNA gene sequences and restriction endonucleaseanalysis (ARDRA). In:AKKERMANS A.D.L.,VANELSAS, J.D.,DEBRUIIN,F.J.(Eds).MolecularMicrobial Ecology Manual. Dordrechet (The Netherlands): Kluwer Academic, 1995. p.3.3.2/1-3.3.2/8.

Pitcher, D.G.; Saunders, N.A.; Owen, R.J. Rapid extraction of bacterial genomic DNA with guanidium thiocyanate. Letters in Applied Microbiology, v.8, p.151156, 1989.

Thompson, J.D.; Gbson, T.J.; Plewniak, F.; Jeanmougin, F.; Higgins, D.G. The ClustalX windows interface, flexible strategies for multiple sequence alignment aided by quality analysis tools. Nucleic Acids Research, v.24, p.4876-4882, 1997.

Recebido em 11/9/06

Aceito em 2/8/07 